\title{
A PEDAGOGIA DA PERGUNTA COMO ESTRATÉGIA DIDÁTICA NA AULA DE GEOGRAFIA
}

\author{
The pedagogy of the question as a didactic strategy in the geography school \\ Elaine Cristina Soares Surmacz \\ Claudivan Sanches Lopes** \\ ${ }^{*}$ Universidade Estadual de Maringá - elainesurmacz@gmail.com. \\ ** Universidade Estadual de Maringá - claudivanlopes@gmail.com.
}

Recebido em 06/08/2018. Aceito para publicação em 20/08/2018.

Versão online publicada em 03/09/2018 (http://seer.ufrgs.br/paraonde)

\begin{abstract}
Resumo:
Esse artigo apresenta o resultado de uma pesquisa que teve como objetivo compreender o papel da pergunta na aprendizagem geográfica a partir da percepção de professores de Geografia que atuam em escolas de educação básica no Estado do Paraná. Os sujeitos da pesquisa foram dez professores, o objeto da pesquisa, a pergunta do aluno em sala de aula. A Metodologia privilegiou aspectos qualitativos. Os dados coletados foram categorizados a partir das respostas coletadas por meio de questionário. Como resultado, obtivemos que a pergunta na aprendizagem dos conteúdos geográficos é uma ferramenta estratégica importante, pois possibilita a aprendizagem de forma colaborativa. A pergunta por parte do aluno pode ser entendida como um sinal de interesse pela aula e quando bem utilizada pelo professor pode ser uma ferramenta importante de avaliação da aprendizagem.
\end{abstract}

Palavras-chave: Estratégia didática; Ensino de Geografia; Pedagogia da pergunta.

\begin{abstract}
:
This article presents the results of a research that aimed to understand the role of the question in geographic learning from the perception of Geography teachers who work in basic education schools in the State of Paraná. The subjects of the research were ten teachers, the object of the research, the student's question in the classroom. The methodology focused on qualitative aspects. The data collected were categorized from the answers collected through a questionnaire. As a result, we obtained that the question in the learning of the geographic contents is an important strategic tool, because it enables the learning of collaborative form. The question on the part of the student can be understood as a sign of interest in the class and when well used by the teacher can be an important tool to evaluate the learning..
\end{abstract}

Key-words: Didatic strategy; Geography teaching; Pedagogy of question.

\section{Introdução}

Todo conhecimento se produz a partir de uma curiosidade ou de uma pergunta. Dessa forma, estimular a curiosidade pode ser a melhor forma de despertar o aluno para o saber. A curiosidade colabora de forma significativa na formação do pensamento reflexivo. Nesse sentido, aulas interativas mediadas por perguntas são "vivas" e se constituem essenciais no processo de aprendizagem.

Aulas sem questionamentos, não desempenham seu papel central: o diálogo dos conhecimentos. Em síntese, aulas sem perguntas são cansativas e tendem a ser referenciadas no paradigma tradicional 
da suposta "transmissões do conhecimento" por parte do professor aos seus alunos.

No contexto exposto, os alunos são tolhidos da ação de participantes ativos no processo de construção e reconstrução de seus conhecimentos (DEMO, 2007). Entende-se, portanto, que o uso da pergunta como estratégia de ensino, reúne condições para que os conteúdos disciplinares trabalhados em sala de aula tornem-se interessantes e significativos na percepção do aluno. Em outras palavras, “[...] o que o professor deveria ensinar - porque ele próprio deveria sabê-lo seria, antes de tudo, ensinar a perguntar. Porque o início do conhecimento, repito, é perguntar". (FREIRE, FAUNDEZ, 1985, p.46). Dentro dessa perspectiva, cabe observar que as respostas apenas devem surgir quando houver questionamentos e não ao contrário.

Diante do expressado, o presente texto traz o resultado de uma pesquisa que buscou compreender o papel da pergunta na construção do conhecimento geográfico a partir do olhar do professor de Geografia de escolas de educação básicas, localizadas nos municípios de Rio Azul, Irati e União da Vitória, todos pertencentes ao Estado do Paraná.

\subsection{A interação o aluno por meio da pergunta nas aulas de Geografia}

A maneira pelo qual o professor esquematiza suas práticas é uma das condições que determina o maior ou o menor interesse por parte dos alunos pelos conteúdos trabalhados em sala e, isso vai interferir de forma eloquente no modo como a aula transcorre. Assim, atribuir valor a pergunta do aluno é um meio de permitir que a dúvida se instale em sala de aula e as "verdades" sejam questionadas/inquiridas.

As perguntas possuem um papel mediador, é uma ponte entre a pergunta primeira e a realidade concreta. (FREIRE, FAUNDEZ, 1985). 0 ato de perguntar, ou mesmo a própria pergunta, são princípios de conhecimento. É importante observar que "[...] o valor não está tanto nas respostas que o professor oferece, porque as respostas são sem dúvida provisórias, assim como as perguntas.(FREIRE, FAUNDEZ, 1985).

Nesse aspecto, existe a necessidade de estimular permanentemente a curiosidade do aluno por meio do ato de perguntar, em lugar de reprimir. Assim, ao optar pela pedagogia da pergunta como estratégia pedagógica o professor introduz em sala de aula um ambiente real de aprendizagem com condições de promoção da interação entre os sujeitos, que, mediados por perguntas, exibem suas inquietações, compreendidas como resultado de necessidades não satisfeitas. (BÖOK, 2008).

Dito isso, observa-se, que a pergunta em sala de aula solicita confrontos entre saberes, promove a dúvida e a curiosidade, originando novos conhecimentos.

\section{Desenvolvimento}

A metodologia tradicional de ensino-aprendizagem centra-se na ação de transferência de conhecimento. 0 professor é tomado como mensageiro desse e, "repassa" aos alunos, que, por sua vez, necessitam decorá-los para logo serem conferidos pelo professor por meio de uma prova. Essa forma de conceber a aprendizagem diverge muito dos princípios defendidos por Paulo Freire (1996). Pois, a ação de ensinar vai além do transmitir conhecimento, é uma forma de assegurar ao aluno a possibilidade de construção e de produção de seu próprio saber.

Partindo desse ponto de vista, compreende-se que ensinar Geografia através do diálogo, do questionamento é uma alternativa relevante, pois, valoriza o discurso em sala de aula e também oportuniza ao professor um novo olhar sobre como os seus alunos aprendem. Nasce nesse contexto uma forma de parceria de estudo entre professor e aluno.

Essa forma de diálogo entendido nas palavras de Freire (1996, p.115) como: 
Uma relação horizontal de A com B. Nasce de uma matriz crítica e gera criticidade (Jaspers). Nutre-se do amor, da humildade, da esperança, da fé, da confiança. Por isso, só o diálogo comunica. E quando os dois polos do diálogo se ligam assim, com amor, com esperança, com fé um no outro, se fazem críticos na busca de algo. Instala-se, então, uma relação de simpatia entre ambos. Só aí há comunicação.

Nessa forma de comunicação oportunizada pelo diálogo "o educador já não é o que apenas educa, mas o que, enquanto educa, é educado, em diálogo com o educando que, ao ser educado, também educa." (FREIRE, 2005, p. 79). Ou seja, tanto o professor, como o aluno, crescem juntos e estabelece uma relação mais afetiva, o ensino acontece de forma prazerosa e mais significativa.

No que se refere aos conteúdos geográficos e ao professor de Geografia Freire $(2005, \mathrm{p}, 14)$ contribui afirmando que esse:

\begin{abstract}
Tem que saber o que os alunos pensam sobre os conceitos-chave desta ciência, como: Espaço, Região, Território, Paisagem e Lugar. Para que se possa aproveitar o que os educandos já sabem de coerente e superar o erro que eles possuem sobre tais conceitos. Sendo assim, o professor de geografia estará despertando a curiosidade de seus educandos, que através de um processo de aprendizagem passará de ingênuo para a epistemológica (FREIRE, 2005, p.14).
\end{abstract}

Reafirma-se, portanto, que no ensino de Geografia, o diálogo na perspectiva de Paulo Freire é um fenômeno essencial e também uma categoria efetiva na práxis pedagógica. Pois, se entende, que o diálogo requer ação-reflexão, e neste contexto, a reflexão é um elemento dos homens e não dos animais. 0 diálogo como opção ao ensino dos conteúdos geográficos: Espaço, Território, Região, Lugar, permite reflexão por parte do professor que é comprometido com a promoção de uma sociedade mais justa e humana.

Neste sentido, Freire vai oferecer suportes teóricos para práxis educativa no ensino da Geografia, visto que suas ideias e práxis em relação ao mundo são relevantes na educação Geográfica.

\title{
3. Metodologia da pesquisa
}

A pesquisa foi realizada com professores de Geografia da rede pública de ensino do Estado do Paraná. Esses, atuantes nos municípios de Rio Azul, Irati e União da Vitória, no Estado do Paraná. A abordagem da pesquisa é de cunho qualitativo, na busca do entendimento dos sujeitos (professores) da pesquisa sobre a pergunta do aluno nas aulas de Geografia (BORGAN; BIKLEIN, 2010).

0 universo da pesquisa esteve composto de 12 professores de Geografia e a amostra consistiu no número de professores que responderam e devolveram o questionário, totalizando 10 professores.

Os questionários foram remetidos via E-mail, num total de 12 questionários. Os professores eleitos fazem parte do quadro de funcionários de diferentes escolas localizadas em três municípios distintos da região sul do Estado do Paraná como já mencionado.

Nas citações dos depoimentos, os sujeitos da pesquisa, serão identificados no texto por letras, ex: (P1; P2 etc.). A preocupação está na preservação de suas identidades. Os depoimentos constituem-se em resposta a seguinte questão: Qual a importância da pergunta na sala de aula para a aprendizagem dos conteúdos geográficos?

Para análise dos depoimentos utilizou-se da Análise de Conteúdo de Franco (2008) que tem por base Bardin (1977) e, ocorreu por meio da categorização das unidades de sentido e da produção de textos interpretativos. 


\subsection{Análise dos resultados e discussões}

Dos 12 questionários enviados, obteve-se retorno de 88\% deles. De modo geral, os professores, consideram a pergunta em sala de aula como um elemento importante caracterizador da aprendizagem, afirmam também, que a partir da pergunta é possível medir o interesse do aluno pela aula e pela temática trabalhada. Destaca-se na análise a observância de que "o valor da pergunta está no fato de que esta parte do interesse, da curiosidade do aluno" $(P 1,2017)$. Adiante se apresenta algumas categorias identificadas nos depoimentos dos sujeitos pesquisados.

1- Relacionado ao interesse:

"A pergunta do aluno é sinal de interesse pela aula" $(P 1,2017)$. A partir da pergunta é possível o professor criar situações de comunicação com o aluno com propósito educativo, tem condições ainda de procurar meios, caminhos e interferir pouco, muito ou nada. E possível também colocar os alunos como sujeitos de sua própria reflexão, utilizando-se de sua curiosidade natural.

0 entendimento da pergunta como uma forma do professor avaliar sua estratégia de ensino aparece nos depoimentos na seguinte expressão: "A pergunta, no final das contas, é um troféu para o professor, onde ele pode avaliar o quando sua aula é interessante e/ou importante para a vida do aluno." (P7, 2017). Nessa perspectiva, é importante destacar que o professor é percebido como um mediador e, a qualidade dessa "mediação interfere nos processos intelectuais, afetivos e sociais do aluno, ele tem tarefas importantes a cumprir". (CAVALCANTI, 2002, p.20).

\section{2- Relacionado à forma de abordagem}

"Valorizar a pergunta do aluno e desta fazer um gancho para a abordagem"(P2). A manifestação do aluno em sala de aula é considerada um momento para que o professor apreenda o conhecimento prévio do aluno e perceba qual forma de abordagem se faz mais adequada nessa circunstância. Nessa situação, a postura adotada pelo professor vai contribuir de forma significativa como sugere as palavras de (P9, 2017) : "A forma como o professor aborda seu conteúdo também contribui para que o aluno se interesse pelo assunto e com isso passe a questionar".

É importante destacar, que no processo de ensino-aprendizagem dos conteúdos geográficos o interesse do aluno pelos temas trabalhados é de fundamental importância. Sem interesse não há aprendizagem.

O papel da geografia é levar o aluno a "compreender o espaço produzido pela sociedade em que vivemos hoje, suas desigualdades e contradições, as relações de produção que nela se desenvolvem e a apropriação que essa sociedade faz da natureza". (OLIVEIRA, 2003, p. 142). Sendo assim, não se percebe a existência de aprendizagem sem a participação efetiva do aluno no processo. Porque, o pensar e o "fazer" o espaço geográfico exige abertura de pensamento por parte do aluno acerca do mundo, nas diferentes escalas geográficas. Nessa situação o interesse, a curiosidade do aluno são peças chaves para a aprendizagem.

\section{3- Relacionado à avaliação}

A pergunta é de "grande relevância, pois se torna um importante instrumento de avaliação reciproca $(P 3,2017) "$. A pergunta possibilita que o professor faça reflexões sobre como anda sua comunicação com os alunos, a qualidade do seu planejamento. Mas, não se está falando de uma reflexão apenas consigo mesmo e, sim, fundamentada em teorias consistentes que de ao professor suporte para compreender e transformar sua aula de acordo com as necessidades observadas no decorrer da aula como sugere um dos trechos do depoimento do (P8,2017): “A pergunta é na verdade o complemento da aula, onde o aluno com suas questões ajuda o professor a responder aquilo que, por ventura, havia fugido de seu plano de aula e que estava contemplado em sua programação" Ou seja, a pergunta se constitui uma forma importante de verificar se o objetivo da aula está sendo atingindo. Nas palavras de Libânio (1994, p. 250) “0 trabalho docente nunca é unidirecional. 
As respostas e opiniões mostram como eles estão reagindo à atuação do professor, às dificuldades que encontram na assimilação dos conhecimentos. Servem, também, para diagnosticar as causas que dão origem a essas dificuldades. Diagnosticado as falhas é possível trabalhar para a melhora do ensino.

\title{
4- Relacionado à estratégia
}

Segundo (P4, 2017). "O não questionamento do aluno traz dificuldade para o professor adequar as estratégias de ensino mais eficazes no processo de aprendizagem". Essa observação vem validar o entendimento de que por mais que um professor busque em seu planejamento adequar suas estratégias de ensino para melhorar o processo de aprendizagem, sem a participação do aluno a reflexão de seus métodos não será satisfatória. Por outro lado, houve professor que prefere que a pergunta seja lançada por ele "Prefiro eu mesma formular as questão para os alunos" (P10, 2017). Nesse caso, em que o predomínio do entendimento de que é o professor que deve formular as questões em sala de aula pode ter sua raiz ligada a uma pedagogia empirista de ensino. (BECKER, 2001). Na qual o saber e as perguntas devem ter como fonte o professor.

\section{5- Relacionado à motivação}

De acordo com Libâneo (2009) quando se discute motivação em sala de aula, é importante compreender, que é função do professor nortear, direcionar e mesmo intervir para que os alunos sintam-se motivados, realizando a mediação didática. Essa afirmação vem de encontro com as palavras oferecidas pelo (P6, 2017) "O aluno motivado, quer conhecer mais, vai atrás de outras fontes e com isso o tema trabalhado em sala de aula vira objeto de pesquisa". Para Gauthier (1998, p.204) existem meios pelos quais um professor pode estimular seus alunos de maneira positiva, visando um desempenho satisfatório:

\begin{abstract}
Adaptar a tarefa aos interesses dos alunos; incluir um pouco de variedade e de novidade; permitir que os alunos escolham ou tomem decisões de modo autônomo; fornecer aos alunos ocasiões para responder ativamente; fornecer retroação imediata às respostas dos alunos; permitir que os alunos criem um produto acabado; incluir um pouco de fantasia e elementos de estimulação; incorporar às aulas situações lúdicas; prever objetivos de alto nível e questões divergentes e fornecer aos alunos ocasiões para interagir com outros.
\end{abstract}

Percebe-se, portanto, que a pergunta, vem de uma dúvida do aluno que gera uma busca, uma procura, e ao buscar resposta, o aluno reconstrói seu questionamento (DEMO, 2007). Essa situação é parte do processo de aprendizagem que culmina na reconstrução do conhecimento. Nesse aspecto, é possível perceber que o desejo de conhecimento é essencial no processo de aprendizagem, além das experiências vividas pelo aluno.

Sobre as experiências anteriores vividas pelos alunos Vygotsky (1984, p.94) argumenta que "qualquer aprendizado com o qual a criança se defronta na escola tem sempre uma história prévia". Assim, a pergunta que o aluno faz em sala serve de termômetro para o professor verificar os conhecimentos trazidos pelo aluno. Nesse momento o professor busca construir com o aluno novos conceitos e "corrigir" alguns equivocados.

Nas palavras de Moreira (2006) os conhecimentos prévios dos alunos estão em constante construção e que essa relação entendida como dialética é que oportuniza uma aprendizagem significativa e progressiva.

Nesse contexto, observa-se, que a atividade docente é assinalada pelo desafio constante dos profissionais da educação em estabelecer relações interpessoais com os alunos, de modo que o processo de ensino-aprendizagem esteja articulado e que os métodos de ensino utilizados pelo professor cumpram os objetivos a que se propõem. Nas palavras de Callai (1995, p,131 ), ensinar seria:

Conduzir um trabalho que coloque aos alunos às informações, as diversas possibilidades de 
encontrá-las e oportunizar-lhes os instrumentais metodológicos para que possam organizar/construir o seu próprio conhecimento. É no fundo fazer a mediação do trabalho do aluno com o saber.

Dessa forma, é importante destacar que a atualização didática do professor tem a necessidade de acontecer de forma constante. Correndo o risco de não ter condições de acompanhar o ritmo deste novo cenário educacional que se apresenta nos dias atuais. A falta de sintonia entre procedimentos, métodos e estratégias de ensino com o perfil dos alunos é uma das possíveis consequências geradas pela falta de atualização pelo professor de suas práticas de ensino. 0 que poderá prejudicar o processo de ensino-aprendizagem.

\section{Considerações Finais}

Ao refletir sobre o depoimento dos professores de geografia, sobre o papel da pergunta em sala de aula é possível inferir que todos os pesquisados consideram a pergunta uma ferramenta importante no processo de ensino-aprendizagem. Observa-se ainda, que os questionamentos originados pelos alunos fazem com que os professores se sintam mais seguros sobre suas práticas.

0 momento da pergunta é um espaço relevante para identificar os conhecimentos prévios dos alunos; perceber se estão envolvidos na temática. Além de uma ocasião para promoção do diálogo em sala de aula. Entende-se ainda que, o espaço da pergunta também é um lugar para se propor a pesquisa.

A pergunta em sala de aula também melhora a relação entre o professor e os alunos e ainda permite avaliações da qualidade do ensino-aprendizagem. Já que se constitui em um momento de interpretar a existência de sinais de motivação e interesse pela aula e pela temática trabalhada por parte dos alunos.

De modo geral, a pergunta permite uma dinâmica intensa na sala de aula, por se constituir de trocas de conhecimento. É uma ferramenta estratégica importante que possibilita a aprendizagem de forma colaborativa.

A pergunta quando originada do aluno pode ser entendida como um sinal de interesse pela aula e se bem utilizada pelo professor, pode ser uma ferramenta importante de avaliação da aprendizagem e do seu planejamento. Nesse processo, aprende o professor e aprende o aluno. Porém, existem ainda, situações de ensino que mantem como base uma pedagogia empirista, onde o professor é que detém o saber.

\section{Referências}

BECKER, Fernando. Educação e construção do conhecimento. Porto Alegre: Artmed, 2001.

BÖCK, Vivien Rose. Motivação para aprender e motivação para ensinar: reencantando a escola. Porto Alegre: CAPE, 2008.

CARNEIRO, Roberta Pizzio. Reflexões acerca do processo ensino aprendizagem na perspectiva freireana e biocêntrica. Revista Thema. 2012, p.1-18. Disponível em: file://C:/Users/WINDOWS\%2010/Downloads/145-414-2-PB.pdf. Acesso em 23/05/2017.

CAVALCANTI, Lana de Souza. Geografia e prática de ensino. Goiânia: Alternativa, 2002.

FREIRE, Paulo; FAUNDEZ, Antonio. Por uma pedagogia da pergunta. Rio de Janeiro: Paz e Terra, 1985. Disponível Em: http://www.dhnet.org.br/direitos/militantes/paulofreire/paulo freire por uma pedagogia da perg 
unta.pdf. ACESSO EM: 25/05/2017.

FREIRE, Paulo. Pedagogia da autonomia: saberes necessários à prática educativa. São Paulo: Paz e Terra, 1996.

FREIRE, Paulo. Pedagogia do Oprimido. 49o ed. Rio de Janeiro: Paz e Terra, 2005.

GAUTHIER, C. et al. Por uma teoria da pedagogia: pesquisas contemporâneas sobre o saber docente. Ijuí (RS): UNIJUÍ, 1998.

LIBÂNEO, José Carlos. Didática. São Paulo: Cortez Editora, 1994.

OLIVEIRA, A. U. Educação e ensino de Geografia na realidade brasileira. In: OLIVEIRA, A. U. et al (Org.). Para onde vai o ensino de Geografia?. 8. ed. São Paulo: Contexto, 2003. p. 135-144.

VYGOTSKY, L. S. A formação social da mente: o desenvolvimento dos processos psicológicos superiores. 4 ed. São Paulo: Martins Fontes, 1991. 191p. 